ఠ RAPID COMMUNICATION

\title{
A phase I pharmacokinetic study of ursolic acid nanoliposomes in healthy volunteers and patients with advanced solid tumors
}

This article was published in the following Dove Press journal:

International Journal of Nanomedicine

3 January 2013

Number of times this article has been viewed

\author{
Zhongling Zhu ${ }^{1,4}$ \\ Zhengzi Qian ${ }^{2,4}$ \\ Zhao Yan ${ }^{1,4}$ \\ Cuicui Zhao 2,4 \\ Huaqing Wang ${ }^{2,4}$ \\ Guoguang Ying ${ }^{3,4}$ \\ 'Department of Clinical Pharmacology, \\ ${ }^{2}$ Department of Lymphoma, \\ ${ }^{3}$ Laboratory of Tumor Cell Biology, \\ Tianjin Medical University Cancer \\ Institute and Hospital, Tianjin, People's \\ Republic of China; ${ }^{4} \mathrm{Key}$ Laboratory \\ of Cancer Prevention and Therapy, \\ Tianjin, People's Republic of China
}

Correspondence: Zhao Yan Huan-Hu-Xi Road, He-Xi District,

Tianjin, People's Republic of China

Tel +8622 23340 I 23 ext 64I 2

Email yanzhaotj@I26.com

Huaqing Wang

Huan-Hu-Xi Road, He-Xi District.

Tianjin, People's Republic of China

Tel +862223340I23 ext 3210

Email huaqingw@medmail.com.cn
Background: Ursolic acid is a promising anticancer agent. The current study aims to evaluate the single- and multiple-dose pharmacokinetics (PK) as well as the safety of ursolic acid nanoliposomes (UANL) in healthy volunteers and in patients with advanced solid tumors.

Methods: Twenty-four healthy volunteers in the single-dose PK study were divided into three different groups, which received 37, 74, and $98 \mathrm{mg} / \mathrm{m}^{2}$ of UANL. Eight patients in the multiple-dose PK study were administered with $74 \mathrm{mg} / \mathrm{m}^{2}$ of UANL daily for 14 days. The UA plasma concentrations were determined using ultra-performance liquid chromatograph-tandem mass spectrometry.

Results: The plasma concentration profiles of all subjects were characterized by a biexponential decline after infusion. The mean peak plasma concentration $\left(C_{\max }\right)$ increased linearly as a function of the dose $(r=0.999)$. The mean area under the plasma concentration-time curve $(A U C)$ from 0 to 16 hours also increased proportionally with dose escalation $(r=0.998)$. However, the clearance was constant over the specific dose interval. In the multiple-dose PK study, the trough and average concentrations remained low. The mean $A U C$, half-life, $C_{\max }$, time to $C_{\max }$, and the volume of distribution on the first day were similar to those on the last day. All subjects tolerated the treatments well. Most UANL-associated adverse events varied from mild to moderate.

Conclusions: UANL exhibits relatively linear PK behavior with dose levels from $37 \mathrm{mg} / \mathrm{m}^{2}$ to $98 \mathrm{mg} / \mathrm{m}^{2}$. No drug accumulation was observed with repeated doses of UANL. The intravenous infusion of UANL was well tolerated by healthy volunteers and patients with advanced tumors.

Keywords: ursolic acid, nanoliposomes, pharmacokinetics, solid tumor, ultra-performance liquid chromatography, tandem mass spectrometry

\section{Introduction}

Ursolic acid (UA; $3 \beta$-hydroxy-urs-12-en-28-oic acid) is a naturally derived pentacyclic triterpene acid that is widely present in food, medicinal herbs, and other plants. ${ }^{1}$ Its extensive pharmacological effects include hepatoprotective, antioxidant, anti-inflammatory, antiviral, and cytotoxic activities. In recent years, UA has become a major focus in cancer research because of its activities at various stages of tumor development and its low toxicity. Although the concrete mechanisms of its anticancer effects are poorly understood, several studies have found that UA can inhibit proliferation and induce apoptosis of many tumor cell lines. ${ }^{2}$ UA-induced apoptosis occurs through multiple pathways such as the inhibition of DNA replication, ${ }^{3}$ induction of $\mathrm{Ca}^{2+}$ release, ${ }^{4}$ activation of caspases ${ }^{5,6}$ and c-Jun N-terminal kinase, ${ }^{7,8}$ phosphorylation of glycogen synthase kinase $3-\beta$, downregulation of antiapoptotic genes, ${ }^{9}$ inhibition 
of cyclooxygenase- 2 and inducible nitric oxide synthase, ${ }^{10,11}$ suppression of matrixmetallopeptidase- $9,{ }^{12}$ and the inhibition of protein tyrosine kinase, ${ }^{13}$ phosphatidylinositol-3-kinase, ${ }^{14}$ single transducer and activator of transcription $3,{ }^{15}$ adenosine $5^{\prime}$-monophosphate-activated protein kinase, ${ }^{16}$ and nuclear factor $\kappa$-light-chain-enhancer of activated $B$ cells ${ }^{17}$ pathways. Furthermore, UA can inhibit the differentiation, angiogenesis, invasion, and metastasis of tumor cells as well as interfere with numerous enzymes such as those directly involved with DNA synthesis and repair. ${ }^{2,18-20}$

However, because of its poor solubility in water, the oral administration of UA often causes its low bioavailability. ${ }^{21}$ The literature has limited data on the mechanism of absorption and pharmacokinetics (PKs) of UA. A previous study using a Caco-2 cell monolayer model suggested that the main mechanism involved in the absorption of UA was passive diffusion and P-glycoprotein transporter mediated active transport. Liao et al performed a PK study of UA in rats after administration of the traditional Chinese medicinal preparation, Lu-Ying extract. ${ }^{22}$ The results showed that the absorption of UA was rapid, with the peak concentration occurring 1 hour after oral administration of Lu-Ying extract. Although the oral administration dose of Lu-Ying extract contained UA $80.32 \mathrm{mg} / \mathrm{kg}$, its concentrations in rat plasma were extremely low. Recently, a PK study of UA in rats showed that the time to peak concentration of UA in plasma was about 30 minutes, indicating that UA was rapidly absorbed. The half-life of UA in plasma was less than 1 hour, indicating that UA was rapidly eliminated. ${ }^{23}$ Thus, the therapeutic development of UA was limited by its low bioavailability and the enhancement of UA solubility is a real challenge for its development. The nanocarrier-mediated drug delivery system has been used to improve the therapeutic activity and safety of drugs for years. The nanoliposomal formulation is a promising approach for poorly water-soluble drugs. ${ }^{24}$ Thus, UA nanoliposomes (UANL) were developed for the first time in the People's Republic of China. The intravenous (IV) administration of UANL is considered to improve bioavailability because the nanoparticles bypass the stomach. To date, a wide range of preclinical studies in China have been completed ( $\mathrm{Li}$, unpublished data, 2005). These studies revealed that the nanoliposome-encapsulated UA inhibited the growth of various human cancer cells and nude mice xenografts. A further unpublished study has shown that UANL induces minimal toxic effects even with long-term application. Tissue distribution experiments in mice suggested that UANL first enters the stomach and intestines, and then its concentrations decline rapidly. Conversely, the hepatic UA concentration increased rapidly, and exceeded the UA concentrations in the stomach and intestines at 4 hours after IV injection. The results demonstrated that UANL delivers UA to the liver, where it accumulates. Consequently, the drug disposition behavior changes in vivo, and the toxic and side effects of UA on other tissues is decreased (unpublished data). The antitumor activities of UA and the minimal toxic effects that were observed in preclinical studies promoted the human clinical trials of UANL. Thus, a PK study on UANL was started by the Tianjin Medical University Cancer Institute and Hospital.

To date, no PK studies of UANL in humans have been reported. This study is the first report of a PK investigation of UANL in humans. Thus, this study aimed to characterize the PK profiles of UANL in healthy Chinese volunteers and in Chinese patients with advanced solid tumors, as well as to monitor the UANL toxicities after IV administration.

\section{Patients and methods Selection of healthy volunteers and patients}

This present study was performed in accordance with the principles of the Declaration of Helsinki and was approved by the Institutional Review Board of Tianjin Cancer Hospital. All subjects were informed about the study program and signed informed consent forms before participating in the study. The healthy volunteers in the single-dose PK study were chosen based on the following criteria: aged 18 years to 75 years; with normal organ function throughout the body; no drug administration for 2 weeks prior to participation in the study; good living habits; willingness to consume no cigarettes or alcohol during the entire treatment period; and good compliance with the study program requirements. Patients with histologically confirmed solid tumors that had proven intractable to standard therapy or had received no standard therapy were eligible for the multiple-dose PK study. One inclusion criterion for the multiple-dose PK study is that the patients had not undergone any operation, chemotherapy, biotherapy, or radiotherapy for 4 weeks before participating in the study. Other inclusion criteria included: aged 18 years to 75 years; Eastern Cooperative Oncology Group (ECOG) status of 0 to 2; survival expectancy of over 3 months; adequate bone marrow function, as defined by a white blood cell count of $\geq 4.0 \times 10^{9} / \mathrm{L}$, an absolute neutrophil count of $\geq 2.0 \times 10^{9} / \mathrm{L}$, a platelet count of $\geq 100.0 \times 10^{9} / \mathrm{L}$, and a hemoglobin level of $\geq 100.0 \mathrm{~g} / \mathrm{L}$; adequate renal function, as defined by serum creatinine $\leq 1.5$ times the upper limit of normal (ULN); adequate hepatic function, as defined by alanine aminotransferase (ALT) level $\leq 1.5 \times \mathrm{ULN}$, aspartate aminotransferase (AST) level $\leq 1.5 \times \mathrm{ULN}$, and a normal total 
bilirubin level; and no obvious cardiac, pulmonary, or psychiatric disorders. Patients with an active infection and serious brain tumors or metastases were excluded from the study. All patients with probable chances of pregnancy were required to use adequate contraception during the entire study.

\section{Study design}

Injectable UANL was supplied by Liyuanheng Pharmaceutical Co, Ltd (Wuhan, China). The UANL was manufactured as a freeze-dried powder, with $3 \mathrm{mg}$ of UANL in each vial. The present study has an open-label, dose-escalation study design. Based on previous pharmacological, toxicological, and tolerability data, ${ }^{25}$ the initial UANL dose for the single-dose PK study was $37 \mathrm{mg} / \mathrm{m}^{2}$. The dosage was sequentially increased to 74 and $98 \mathrm{mg} / \mathrm{m}^{2}$ in the other corresponding dose-assigned groups. Twenty-four patients in the single-dose PK study received 37 , 74 , and $98 \mathrm{mg} / \mathrm{m}^{2}$ of UANL via a 4-hour IV infusion. Eight patients who were enrolled in the multiple-dose PK study received $74 \mathrm{mg} / \mathrm{m}^{2}$ of UANL daily for 2 consecutive weeks.

\section{PK sample collection}

Single-dose PK $4 \mathrm{~mL}$ blood samples were collected at the following time points: before treatment, at $0.5,1$, and 2 hours during the infusion, at the end of the 4-hour infusion, and finally, at 5, 15, and 30 minutes as well as at 1, 1.5, 2, 3, 4, 6,8 , and 12 hours after the infusion.

On the 1st and 14th days of the multiple-dose PK study, $4 \mathrm{~mL}$ blood samples were collected before treatment, at 30 minutes as well as at 1 and 2 hours during the infusion, at the end of the 4-hour infusion, and finally, at 5, 15, and 30 minutes as well as at 1, 1.5, 2, 3, 4, 6, 8, and 12 hours after the infusion. On the 6th, 7th, and 8th days of the study, $4 \mathrm{~mL}$ blood specimens were collected before treatment and at the end of the 4-hour infusion. The samples of plasma were prepared by centrifugation ( 10 minutes at $600 \times \mathrm{g}$ ), and were subsequently stored at $-80^{\circ} \mathrm{C}$ until further analysis.

\section{Analytical assays}

Ursolic acid ( $>99.5 \%$ purity) and glycyrrhetinic acid (internal standard, $>99.5 \%$ purity) were obtained from the National Institute for Food and Drug Control (Beijing, China). High-performance liquid chromatography (HPLC)-grade acetonitrile and methanol were purchased from Fisher Scientific Inc (Fairlawn, NJ, USA). HPLC-grade ethyl acetate was purchased from Concord Technology Co, Ltd (Tianjin, China). HPLC-grade water was prepared using a Milli-Q system (EMD Millipore, Billerica, MA, USA). Analytical grade ammonium formate was purchased from Runjie Chemical Reagent Co, Ltd (Shanghai, China).

The chromatographic system consisted of an ACQUITYTM ultra-performance liquid chromatography (UPLC) system coupled to an ACQUITYTM triple quadrupole mass spectrometry system and $\mathrm{BEH} \mathrm{C}_{8}$ column $(100 \mathrm{~mm} \times 2.1 \mathrm{~mm}$; inner diameter, 1.7 $\mu \mathrm{m}$; Waters Corp, Milford, MA, USA). Data were processed using the MassLynx version 4.1 software (Waters Corp).

The determination of UA in human plasma was performed by UPLC/tandem mass spectrometry (MS/MS) method as previously described. ${ }^{26}$ The lower limit of quantitation (LLOQ) for UANL was $10 \mathrm{ng} / \mathrm{mL}$, and the assays were linear from $10 \mathrm{ng} / \mathrm{mL}$ to $5000 \mathrm{ng} / \mathrm{mL}$. The mean extraction recovery of UANL was $73.2 \%$, and the matrix ion suppression ranged from $-11.4 \%$ to $-5.6 \%$. The intra- and interday precisions were less than $7.0 \%$ and $7.2 \%$, respectively. The accuracy of UANL was within $\pm 2.0 \%$.

\section{PK data analysis and statistical analysis}

The plasma concentration vs time data were analyzed using noncompartmental methods. The DAS 2.1 PK analysis system (Anhui, China) was used to assess the PK parameters. The peak plasma concentration $\left(C_{\max }\right)$ and the time-to-peak plasma concentration $\left(T_{\max }\right)$ were obtained via the experimental observations. The elimination half-life $\left(t_{1 / 2}\right)$ was calculated as $0.693 / \lambda z$ ( $\lambda z$ is the slope of the terminal phase). The area under the curve $(A U C)$ of the plasma concentration versus time from zero to infinity $\left(A U C_{0-\infty}\right)$ was equivalent to the sum of the areas from time $T_{0}$ to the time of the last measured concentration. Its value was calculated using the linear trapezoidal method (until $C_{\max }$ ), the log-trapezoidal method (until the last measurable concentration), and the extrapolated area. The extrapolated area was determined by dividing the final measured concentration by the slope of the terminal log-linear phase. Trough values on the 6th, 7th, and 8th days were averaged for each dose level. All statistical tests were two-tailed, and significance was set at the 0.05 level. Differences in the mean values of the physical examinations and in the PK parameters among the three groups were compared by analyses of variance or the Kruskal-Wallis test using the Statistical Package for the Social Sciences (SPSS) software (version 16.0; IBM, Armonk, NY, USA). The $t$-test or Wilcoxon's test were used to investigate the differences between the two groups.

\section{Results \\ Subject characteristics}

Thirty-two eligible and consenting subjects were recruited for this study. Twenty-four healthy volunteers were enrolled in the 
single-dose PK study, whereas there were eight patients in the multiple-dose study. The characteristics of the healthy volunteers and patients are shown in Table 1. All healthy subjects had normal results for the physical and laboratory examinations. No statistically significant differences were found in the age, height, weight, body surface area, and body mass index among the three healthy groups. In the multiple-dose PK study, the mean age of the eight patients was 49 years. There were six male and two female patients, all of whom had ECOG performance status score of 0 to 1 . Four patients had non-Hodgkin's lymphoma, two had hepatoma, one had Hodgkin's lymphoma, and one had gastric cancer.

\section{Single-dose PK study in healthy volunteers}

The total UA plasma concentration-versus-time profiles of the healthy volunteers who received 37 to $98 \mathrm{mg} / \mathrm{m}^{2}$ of UANL are shown in Figure 1. The plasma concentration profiles of all subjects were characterized by a biexponential decline after infusion. The major PK parameters at each dose are summarized in Table 2. The respective mean $C_{\max }$ for the subjects in the UANL groups were 1835, 2865, and $3457 \mathrm{ng} / \mathrm{mL}$, in order of increasing UANL dose. The respective mean $A U C_{0-16 \mathrm{~h}}$ were 4203, 7175, and $9696 \mathrm{ng} \cdot \mathrm{hour} / \mathrm{mL}$. The mean $C_{\max }$ increased linearly as a function of dose $(r=0.999)$.
Similarly, the mean area under the plasma concentration-time curve from 0 to 16 hours (designated as $A U C_{0-16 \mathrm{~h}}$ ) increased proportionally with dose escalation $(r=0.998)$. However, the mean $t_{1 / 2}$, volume of distribution $\left(V_{\mathrm{d}}\right)$ and clearance $(C L)$ were not significantly different among the three doses $(P>0.05)$, suggesting that clearance was constant over that specific dose interval. These results show that UANL displays linear PKs after IV administration. No correlation was found between the observed PK profile (in terms of the $A U C$ ) and the patient characteristics (age, height, weight, body mass index, or body surface area).

\section{Multiple-dose PK study in patients with advanced solid tumors}

The mean plasma concentration versus time plot for the eight patients after receiving $74 \mathrm{mg} / \mathrm{m}^{2}$ of UANL during the 14-day period via continuous IV infusion is illustrated in Figure 2. The UANL PK parameters on the first day and the last day for the patients are summarized in Table 3 . The mean steady-state $C_{\max }$, trough concentration $\left(C_{\min }\right)$, and average concentration $\left(C_{\mathrm{av}}\right)$ were $1211,7.31$, and $196 \mathrm{ng} / \mathrm{mL}$, respectively. No accumulation was observed with repeated doses of UANL. Comparison of the PK parameters at $74 \mathrm{mg} / \mathrm{m}^{2}$ between the healthy volunteers and patients showed that $T_{\max }, t_{1 / 2}$, and $V_{\mathrm{d}}$ were not significantly different between the two subject

Table I Summary of healthy volunteer and patient characteristics

\begin{tabular}{|c|c|c|c|c|}
\hline & \multicolumn{3}{|c|}{$\begin{array}{l}\text { Single-dose } \\
\text { pharmacokinetics }\end{array}$} & \multirow{3}{*}{$\begin{array}{l}\begin{array}{l}\text { Multiple-dose } \\
\text { pharmacokinetics }\end{array} \\
74 \mathrm{mg} / \mathrm{m}^{2} \\
\mathrm{~N}=\mathbf{8}\end{array}$} \\
\hline & $37 \mathrm{mg} / \mathrm{m}^{2}$ & $74 \mathrm{mg} / \mathrm{m}^{2}$ & $98 \mathrm{mg} / \mathrm{m}^{2}$ & \\
\hline & $\mathbf{N}=\mathbf{8}$ & $\mathbf{N}=\mathbf{8}$ & $\mathbf{N}=\mathbf{8}$ & \\
\hline \multicolumn{5}{|l|}{ Sex } \\
\hline Male & 8 & 2 & 7 & 6 \\
\hline Female & 0 & 6 & I & 2 \\
\hline \multicolumn{5}{|l|}{ Age (years) } \\
\hline Mean, range & $23(2 \mid-27)$ & $22(20-23)$ & $22(20-27)$ & $49(33-68)$ \\
\hline \multicolumn{5}{|l|}{ Height (cm) } \\
\hline Mean, range & $168(156-178)$ & $165(155-177)$ & I73 (I68-178) & $170(154-178)$ \\
\hline \multicolumn{5}{|l|}{ Weight (kg) } \\
\hline Mean, range & $63(55-72)$ & $57(50-75)$ & $69(54-84)$ & $70(56-96)$ \\
\hline \multicolumn{5}{|l|}{ Body surface area $\left(\mathrm{m}^{2}\right)$} \\
\hline Mean, range & I.7I (I.56-I.86) & $1.63(1.47-1.92)$ & $1.79(1.61-1.98)$ & $1.82(1.53-2.15)$ \\
\hline \multicolumn{5}{|l|}{ BMI $\left(\mathrm{kg} \cdot \mathrm{m}^{-2}\right)$} \\
\hline Mean, range & $22.3(19.0-23.8)$ & $20.9(19.5-23.9)$ & $22.2(19.1-23.9)$ & $24.2(23.6-30.3)$ \\
\hline \multicolumn{5}{|l|}{ ECOG status at entry } \\
\hline $0-1$ & - & - & - & 8 \\
\hline \multicolumn{5}{|l|}{ Tumor types } \\
\hline Non-Hodgkin's lymphoma & - & - & - & 4 \\
\hline Hodgkin’s lymphoma & - & - & - & 1 \\
\hline Hepatoma & - & - & - & 2 \\
\hline Gastric cancer & - & - & - & I \\
\hline
\end{tabular}

Note: Data are expressed as mean (Range).

Abbreviations: BMI, body mass index; ECOG, Eastern Cooperative Oncology Group. 


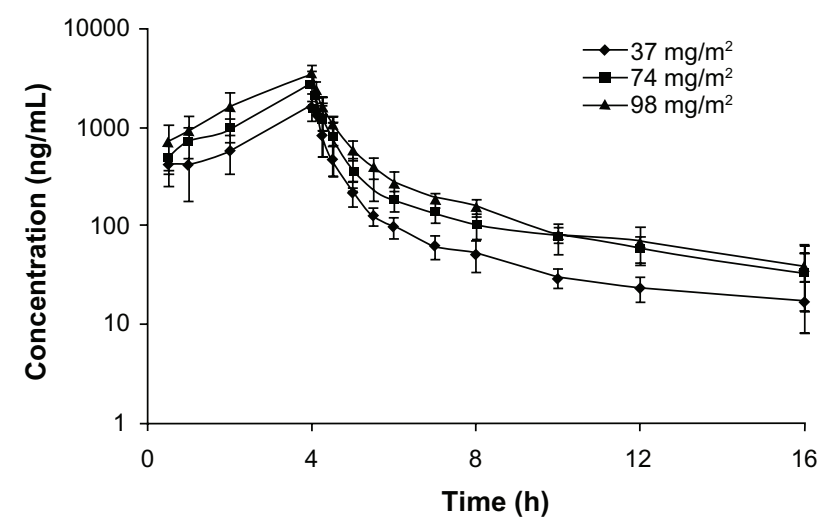

Figure I Mean logarithmic concentration versus time plot after receiving $37 \mathrm{mg} / \mathrm{m}^{2}$ $(\bullet, \mathrm{n}=8), 74 \mathrm{mg} / \mathrm{m}^{2}(\boldsymbol{\square}, \mathrm{n}=8)$, or $98 \mathrm{mg} / \mathrm{m}^{2}(\bullet, \mathrm{n}=8)$ of ursolic acid nanoliposomes intravenously.

groups $(P>0.05)$. However, the mean $A U C, C_{\max }$, and $C L$ were significantly lower in the patients than in the healthy volunteers $(P<0.05)$.

\section{Safety}

The National Cancer Institute's Common Terminology Criteria for Adverse Events (version 3.0) was used to grade adverse events (AEs). Table 4 presents a summary of the toxicities associated with the administration of UANL in healthy volunteers and patients. The IV infusions of UANL were well tolerated by the healthy volunteers and the patients with advanced tumors. All subjects were evaluated for tolerability. No AE was observed in patients who receiving $37 \mathrm{mg} / \mathrm{m}^{2}$ of UANL. The incidence of UANL-associated AEs did not show an increasing trend after the provision of the larger doses. Nausea, diarrhea, and abdominal distention were the common AEs that were observed. Most UANL-associated AEs were either grade 1 or 2 . Only one patient developed grade 3 AEs

Table 2 Main pharmacokinetic parameters after single intravenous doses of ursolic acid nanoliposomes in healthy volunteers

\begin{tabular}{|c|c|c|c|}
\hline \multirow[t]{3}{*}{ Parameters } & \multicolumn{3}{|c|}{ Dose level $\left(\mathrm{mg} / \mathrm{m}^{2}\right)$} \\
\hline & 37 & 74 & 98 \\
\hline & $\mathbf{N}=\mathbf{8}$ & $\mathbf{N}=\mathbf{8}$ & $\mathbf{N}=\mathbf{8}$ \\
\hline$t_{1 / 2}$ (hour) & $4.59(2.44)$ & $4.46(1.4 I)$ & $3.90(2.08)$ \\
\hline$V_{d}\left(L / m^{2}\right)$ & $58.7(33.0)$ & $64.3(17.9)$ & $55.4(28.1)$ \\
\hline CL (L/hour/m²) & $8.67(1.07)$ & $10.20(1.46)$ & $9.94(1.13)$ \\
\hline $\mathrm{AUC}_{0-16 \mathrm{~h}}(\mathrm{ng} \cdot \mathrm{hour} / \mathrm{mL})$ & $4203(588)$ & 7175 (999) & $9696(1134)$ \\
\hline $\mathrm{AUC}_{0-\infty}(\mathrm{ng} \cdot$ hour$/ \mathrm{mL})$ & $4329(556)$ & $7418(1057)$ & 9971 ( I 144) \\
\hline $\mathrm{MRT}_{0-16 \mathrm{~h}}$ (hour) & $3.69(0.36)$ & $3.93(0.37)$ & $3.84(0.34)$ \\
\hline $\mathrm{MRT}_{0-\infty}$ (hour) & $4.29(0.90)$ & $4.56(0.88)$ & $4.4 I(0.95)$ \\
\hline$C_{\max }(\mathrm{ng} / \mathrm{mL})$ & $1835(438)$ & $2865(868)$ & $3457(856)$ \\
\hline$T_{\max }^{\max }(\mathrm{h})$ & $4.03(0.04)$ & $4.02(0.04)$ & $4.00(0)$ \\
\hline
\end{tabular}

Note: Values are expressed as mean (standard deviation).

Abbreviations: $t_{1 / 2}$, half-life; $\mathrm{Vd}$, volume of distribution; $\mathrm{CL}$, clearance; AUC, area under the concentration-time curve; MRT, mean residence time; $C_{\max }$, maximum plasma concentration; $T_{\max }$, time to maximum plasma concentration.

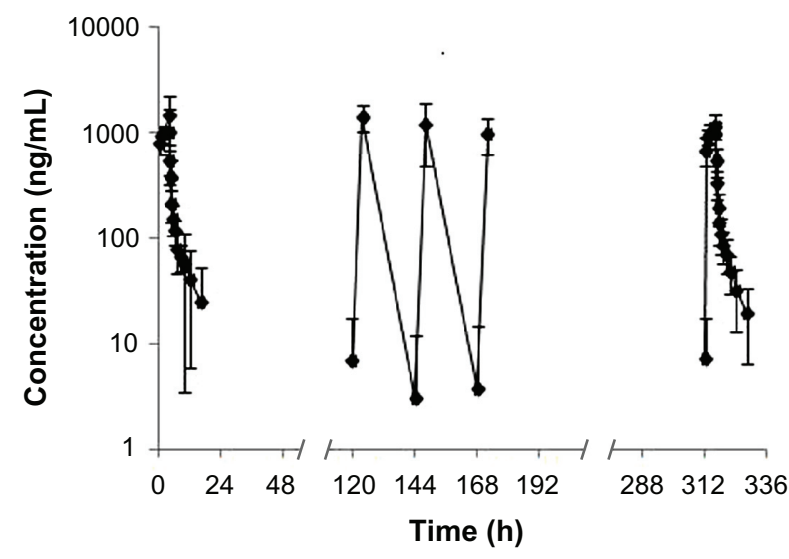

Figure 2 Mean logarithmic concentration versus time plot after receiving $74 \mathrm{mg} / \mathrm{m}^{2}$ ursolic acid nanoliposomes for the 14-day continuous intravenous infusion $(n=8)$.

in the form of elevated AST and ALT levels with diarrhea at the same time after receiving $74 \mathrm{mg} / \mathrm{m}^{2}$ of UANL.

\section{Discussion}

Medicinal plants are often investigated as sources of new drugs for treating cancer. UA is one of the most promising chemopreventive agents for cancer. ${ }^{27}$ The water solubility of UA is limited, which consequently limits its bioavailability in the body. The nanoliposome-encapsulation of UA was expected to increase its bioavailability and therapeutic efficacy. The formulated nanoliposomes prepared in this study were relatively uniform in size. The UANL average diameter was $200 \mathrm{~nm}$, and the average entrapment efficiency determined by dialysis method was 95\%. Conventional UA was found to be mainly distributed in tissues with extensive vascular supply such as the lung, spleen, and liver at 1 hour after oral administration. ${ }^{23}$ However, based on the unpublished preclinical studies on nanoliposomal UA in

Table 3 Main pharmacokinetic parameters at day I and day I4 after multiple doses of ursolic acid nanoliposomes in patients with advanced solid tumors

\begin{tabular}{llll}
\hline Parameters & Day I & Day I4 & $P$ \\
\hline$t_{1 / 2}($ hour $)$ & $4.58(2.04)$ & $4.00(\mathrm{I} .27)$ & 0.563 \\
$\mathrm{~V}_{\mathrm{d}}\left(\mathrm{L} / \mathrm{m}^{2}\right)$ & $88.6(3 \mathrm{I} .8)$ & $89.9(28 . \mathrm{I})$ & 0.947 \\
$\mathrm{CL}\left(\mathrm{L} /\right.$ hour $\left./ \mathrm{m}^{2}\right)$ & $14.40(3.94)$ & $15.80(3.05)$ & 0.383 \\
$\mathrm{AUC}_{0-16 \mathrm{~h}}(\mathrm{ng} \cdot$ hour $/ \mathrm{mL})$ & $5172(\mathrm{II} 36)$ & $4705(873)$ & 0.362 \\
$\mathrm{AUC}_{0-\infty}(\mathrm{ng} \cdot$ hour$/ \mathrm{mL})$ & $5498(\mathrm{I} 525)$ & $4834(933)$ & $0.29 \mathrm{I}$ \\
$\mathrm{MRT}_{0-16 \mathrm{~h}}$ (hour) & $3.34(0.55)$ & $3.30(0.3 \mathrm{I})$ & 0.809 \\
$\mathrm{MRT}_{0-\infty}$ (hour) & $4.3 \mathrm{I}(\mathrm{I} .89)$ & $3.78(0.70)$ & 0.469 \\
$C_{\max }(\mathrm{ng} / \mathrm{mL})$ & $1589(635)$ & $121 \mathrm{I}(204)$ & 0.109 \\
$T_{\max }(\mathrm{h})$ & $3.00(\mathrm{I} .4 \mathrm{I})$ & $3.63(\mathrm{I} .06)$ & 0.279 \\
\hline
\end{tabular}

Note: Values are expressed as mean (standard deviation).

Abbreviations: $\mathrm{t}_{1 / 2}$, half-life; $\mathrm{Vd}$, volume of distribution; $\mathrm{CL}$, clearance; $\mathrm{AUC}$, area under the concentration-time curve; MRT, mean residence time; $C_{\text {max }}$, maximum plasma concentration; $\mathrm{T}_{\max }$, time to maximum plasma concentration. 
Table 4 Numbers of subjects with ursolic acid nanoliposome-associated adverse events

\begin{tabular}{|c|c|c|c|c|c|c|c|c|c|}
\hline \multirow[t]{4}{*}{ Toxicity (CTC) } & \multicolumn{6}{|c|}{ Single-dose groups } & \multirow{3}{*}{\multicolumn{3}{|c|}{$\begin{array}{l}\text { Multiple-dose group } \\
74 \mathrm{mg} / \mathrm{m}^{2} \\
\mathrm{~N}=8\end{array}$}} \\
\hline & \multirow{2}{*}{\multicolumn{3}{|c|}{$\begin{array}{l}74 \mathrm{mg} / \mathrm{m}^{2} \\
\mathrm{~N}=8\end{array}$}} & \multirow{2}{*}{\multicolumn{3}{|c|}{$\begin{array}{l}98 \mathrm{mg} / \mathrm{m}^{2} \\
\mathrm{~N}=8\end{array}$}} & & & \\
\hline & & & & & & & & & \\
\hline & Grade I & Grade 2 & Grade 3 & Grade I & Grade 2 & Grade 3 & Grade I & Grade 2 & Grade 3 \\
\hline \multicolumn{10}{|c|}{ Gastrointestinal disorders } \\
\hline Nausea & 2 & 0 & 0 & 0 & 0 & 0 & 0 & 0 & 0 \\
\hline Diarrhea & 1 & 0 & 1 & 0 & 0 & 0 & 0 & 0 & 0 \\
\hline Abdominal distention & 1 & 1 & 0 & 0 & 0 & 0 & 1 & 0 & 0 \\
\hline \multicolumn{10}{|l|}{ Constitutional } \\
\hline Fever & 1 & 0 & 0 & 0 & 0 & 0 & 0 & 0 & 0 \\
\hline \multicolumn{10}{|l|}{ Metabolic disorders } \\
\hline AST & 0 & 0 & 1 & 0 & 0 & 0 & 0 & 0 & 0 \\
\hline ALT & 0 & 0 & I & 0 & 0 & 0 & 0 & 0 & 0 \\
\hline GGT & 1 & 0 & 0 & I & 0 & 0 & 0 & 0 & 0 \\
\hline TG & & & & 1 & 0 & 0 & 1 & 0 & 0 \\
\hline TBIL & & & & I & 0 & 0 & & & \\
\hline \multicolumn{10}{|l|}{ Pain } \\
\hline Arthralgia & 0 & 0 & 0 & 0 & 0 & 0 & I & 0 & 0 \\
\hline \multicolumn{10}{|l|}{ Skin } \\
\hline Pruritus & 0 & 0 & 0 & 0 & 0 & 0 & I & 0 & 0 \\
\hline
\end{tabular}

Abbreviations: ALT, alannine aminotransferase; AST, aspartate aminotransferase; GGT, $\gamma$-glutamyl transferase; TG, triglyceride; TBIL, total bilirubin.

rats, UANL probably had a lower $V_{\mathrm{d}}$ and higher hepatic drug concentration over conventional UA. These UANL characteristics may contribute towards eliminating its drug-related side effects and nonspecific drug accumulation.

In the present study, we determined the total UA concentration in human plasma by UPLC-MS/MS. ${ }^{26}$ The LLOQ under the present conditions was $10 \mathrm{ng} / \mathrm{mL}$. The results indicated that the method was specific, sensitive, and convenient for the determination of the UA concentration in biological samples. Subsequently, we investigated the PKs and safety of UANL in healthy volunteers and patients with advanced solid tumors. Following a single dose via IV administration, the total UA plasma concentration of all subjects followed a biexponential decline. After the end of the IV infusion, the UA plasma concentration rapidly decreased to a concentration that was approximately ten times less than the peak concentration within 2 hours. The PK characteristics of UANL were linear and dose-proportional in the range of $37 \mathrm{mg} / \mathrm{m}^{2}$ to $98 \mathrm{mg} / \mathrm{m}^{2}$. These results showed that the plasma concentration of the total UA decreased with constant clearance. The preclinical studies of UANL in rats showed a similar trend of the PK profiles ( $\mathrm{Li}$, unpublished data, 2005). In the multiple-dose PK study, the steady-state $C_{\text {min }}$ and $C_{\text {av }}$ remained low. The mean $A U C, t_{1 / 2}, C_{\max }, T_{\max }$, and $V_{\mathrm{d}}$ on the first day were similar to those on the last day, thereby indicating that the PKs of UANL had no apparent changes after repeated administration. These data showed that no drug accumulation was observed with continuous administration of UANL. The mean $A U C, C_{\max }$, and $C L$ in the patients on the first day were significantly lower than those in the healthy volunteer group. Several possible reasons may account for this difference. First, the small sample sizes in the present study may contribute to this large difference. Then, a difference in the hepatic functional reserve of the healthy volunteers and patients may explain their different levels of response to the UANL. Whether this difference can be ascribed to the hepatic metabolic enzymes and/or other catabolic enzymes is unclear.

All subjects in this study tolerated the treatments well. Most UANL-associated AEs varied from mild to moderate and were not dose-related. Only one healthy volunteer developed grade 3 AEs, such as AST and ALT elevation as well as diarrhea at the same time, after receiving $74 \mathrm{mg} / \mathrm{m}^{2}$ of UANL. The most frequently observed AEs included abdominal distention, nausea, and diarrhea. The UANL side effects after the 14-day continuous infusion included grade 1 skin pruritus, arthralgia, and triglyceride elevation. A previous tolerability study in humans had similar results, thereby suggesting that UANL had minimal toxic effects. ${ }^{25}$ The dose-limiting toxicity of UANL was hepatotoxicity. Thus, particular attention should be given to any clinical and laboratory evidence of hepatotoxicity in future clinical studies of UANL. Correlation analyses were conducted to determine if a relationship could be established between the observed PK profiles and UANL toxicities. No correlation was found, possibly because of the small sample size. 


\section{Conclusion}

For the first time, UANL was developed in the People's Republic of China. This study is the first report of a PK investigation of UANL in humans. In the present study, UANL is safe and presents apparent linear PK behavior for dose levels within the range of $37 \mathrm{mg} / \mathrm{m}^{2}$ to $98 \mathrm{mg} / \mathrm{m}^{2}$. No drug accumulation was observed with repeated UANL administration even with 14 days of continuous IV infusion. The IV infusion of UANL was well tolerated by healthy volunteers and patients with advanced tumors. Further Phase II studies of UANL should be conducted to extensively observe its clinical efficacy and safety.

\section{Acknowledgments}

The authors are grateful to Dr Jing Ping from Department of Project Development, Liyuanheng Pharmaceutical Co, Ltd, China (current address: Department of Pharmacy, Asian Heart Hospital, China), for data acquisition and quality control checks.

\section{Disclosure}

The authors report no conflicts of interest in this work.

\section{References}

1. Liu J. Pharmacology of oleanolic acid and ursolic acid. JEthnopharmacol. 1995;49(2):57-68.

2. Sultana N. Clinically useful anticancer, antitumor, and antiwrinkle agent, ursolic acid and related derivatives as medicinally important natural product. J Enzyme Inhib Med Chem. 2011;26(5):616-642.

3. Kim DK, Baek JH, Kang CM, et al. Apoptotic activity of ursolic acid may correlate with the inhibition of initiation of DNA replication. Int J Cancer. 2000;87(5):629-636.

4. Baek JH, Lee YS, Kang CM, et al. Intracellular Ca2+ release mediates ursolic acid-induced apoptosis in human leukemic HL-60 cells. Int J Cancer. 1997;73(5):725-728.

5. Choi YH, Baek JH, Yoo MA, et al. Induction of apoptosis by ursolic acid through activation of caspases and down-regulation of c-IAPs in human prostate epithelial cells. Int J Oncol. 2000;17(3):565-571.

6. Harmand PO, Duval R, Delage C, et al. Ursolic acid induces apoptosis through mitochondrial intrinsic pathway and caspase-3 activation in M4Beu melanoma cells. Int J Cancer. 2005;114(1):1-11.

7. Xavier CPR, Lima CF, Pedro DFN, et al. Ursolic acid induces cell death and modulates autophagy through JNK pathway in apoptosis-resistant colorectal cancer cells. J Nutr Biochem. July 26, 2012. [Epub ahead of print.]

8. Zhang Y, Kong C, Zeng Y, et al. Ursolic acid induces PC-3 cell apoptosis via activation of JNK and inhibition of Akt pathways in vitro. Mol Carcinog. 2010;49(4):374-385.

9. Kassi E, Sourlingas TG, Spiliotaki M, et al. Ursolic acid triggers apoptosis and Bcl-2 downregulation in MCF-7 breast cancer cells. Cancer Invest. 2009;27(7):723-733.

10. Subbaramaiah K, Michaluart P, Sporn MB, et al. Ursolic acid inhibits cyclooxygenase-2 transcription in human mammary epithelial cells. Cancer Res. 2000;60(9):2399-2404.
11. Suh N, Honda T, Finlay HJ, et al. Novel triterpenoids suppress inducible nitric oxide synthase (iNOS) and inducible cyclooxygenase (COX-2) in mouse macrophages. Cancer Res. 1998;58(4):717-723.

12. Cha HJ, Park MT, Chung HY, et al. Ursolic acid-induced downregulation of MMP-9 gene is mediated through the nuclear translocation of glucocorticoid receptor in HT1080 human fibrosarcoma cells Oncogene. 1998;16(6):771-778.

13. Hollosy F, Meszaros G, Bokonyi G, et al. Cytostatic, cytotoxic and protein tyrosine kinase inhibitory activity of ursolic acid in A431 human tumor cells. Anticancer Res. 2000;20(6B):4563-4570.

14. Wu B, Wang $\mathrm{X}$, Chi Z-F, et al. Ursolic acid-induced apoptosis in K562 cells involving upregulation of PTEN gene expression and inactivation of the PI3K/Akt pathway. Arch Pharm Res. 2012;35(3): 543-548.

15. Pathak AK, Bhutani M, Nair AS, et al. Ursolic acid inhibits STAT3 activation pathway leading to suppression of proliferation and chemosensitization of human multiple myeloma cells. Mol Cancer Res. 2007;5(9): 943-955.

16. Zheng Q-Y, Jin F-S, Yao C, et al. Ursolic acid-induced AMP-activated protein kinase (AMPK) activation contributes to growth inhibition and apoptosis in human bladder cancer T24 cells. Biochem Biophys Res Commun. 2012;419(4):741-747.

17. Shishodia S, Majumdar S, Banerjee S, et al. Ursolic acid inhibits nuclear factor-kappaB activation induced by carcinogenic agents through suppression of IkappaBalpha kinase and p65 phosphorylation: correlation with down-regulation of cyclooxygenase 2 , matrix metalloproteinase 9 , and cyclin D1. Cancer Res. 2003;63(15):4375-4383.

18. Kanjoormana M, Kuttan G. Antiangiogenic activity of ursolic acid Integr Cancer Ther. 2010;9(2):224-235.

19. Novotny L, Vachalkova A, Biggs D. Ursolic acid: an anti-tumorigenic and chemopreventive activity. Minireview. Neoplasma. 2001;48(4): 241-246.

20. Ovesna Z, Vachalkova A, Horvathova K, et al. Pentacyclic triterpenoic acids: new chemoprotective compounds. Minireview. Neoplasma. 2004;51(5):327-333.

21. Liu J. Oleanolic acid and ursolic acid: research perspectives. J Ethnopharmacol. 2005;100(1-2):92-94.

22. Liao Q, Yang W, Jia Y, et al. LC-MS determination and pharmacokinetic studies of ursolic acid in rat plasma after administration of the traditional chinese medicinal preparation Lu-Ying extract. Yakugaku Zasshi. 2005;125(6):509-515.

23. Chen Q, Luo S, Zhang Y, et al. Development of a liquid chromatographymass spectrometry method for the determination of ursolic acid in rat plasma and tissue: Application to the pharmacokinetic and tissue distribution study. Anal Bioanal Chem. 2011;399(8):2877-2884.

24. Merisko-Liversidge E, Liversidge GG, Cooper ER. Nanosizing: a formulation approach for poorly-water-soluble compounds. Eur J Pharm Sci. 2003;18(2):113-120.

25. Zhao CC, Qian ZZ, Wang HQ, et al. A phase I clinical trial of ursolic acid nanoliposome for evaluating its single-dose to lerance and safety. Chinese Journal of New Drugs. 2011;20(2):148-151.

26. Xia Y, Wei G, Si D, et al. Quantitation of ursolic acid in human plasma by ultra performance liquid chromatography tandem mass spectrometry and its pharmacokinetic study. J Chromatogr B Analyt Technol Biomed Life Sci. 2011;879(2):219-224.

27. Hsu YL, Kuo PL, Lin CC. Proliferative inhibition, cell-cycle dysregulation, and induction of apoptosis by ursolic acid in human non-small cell lung cancer A549 cells. Life Sci. 2004;75(19):2303-2316. 


\section{Publish your work in this journal}

The International Journal of Nanomedicine is an international, peerreviewed journal focusing on the application of nanotechnology in diagnostics, therapeutics, and drug delivery systems throughout the biomedical field. This journal is indexed on PubMed Central, MedLine, CAS, SciSearch $\AA$, Current Contents ${ }^{\circledR} /$ Clinical Medicine,
Journal Citation Reports/Science Edition, EMBase, Scopus and the Elsevier Bibliographic databases. The manuscript management system is completely online and includes a very quick and fair peer-review system, which is all easy to use. Visit http://www.dovepress.com/ testimonials.php to read real quotes from published authors.

Submit your manuscript here: http://www.dovepress.com/international-journal-of-nanomedicine-journal 